
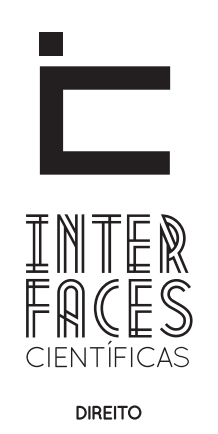

ISSN IMPRESSO 2316-3321

\title{
REFLEXÕES ACERCA DO CONTROLE JUDICIAL DA PREVIDÊNCIA SOCIAL
}

\author{
REFLECTIONS ON THE JUDICIAL CONTROL OF SOCIAL SECURITY
}

REFLEXIONES SOBRE EL CONTROL JUDICIAL DE SEGURIDAD SOCIAL

Renato Santiago Quinta ${ }^{1}$

Jorge Luiz Tesch Santos ${ }^{3}$
Robson Augusto Dainez Condé2

Marcos dos Santos ${ }^{4}$

\section{RESUMO}

O objetivo do presente estudo é promover uma reflexão sobre o controle judicial da previdência social, por meio da consulta à bibliografia especializada. Para conduzir o trabalho em pauta, foram acessadas as bases de dados de periódicos especializados, bem como normas e jurisprudências acerca da temática em questão. Nesse sentido, foram identificadas na jurisprudência decisões que evidenciam o controle judicial na política pública previdenciária. Igualmente, ao se analisar os dispositivos de instruções normativas selecionados na presente pesquisa, verificou-se que aquelas normas foram publicadas de modo a contemplarem comandos judiciais, a despeito de a literatura consultada formular críticas ao ativismo judicial e à exacerbação da exclusão social.

PALAVRAS-CHAVE

Controle Judicial. Seguridade Social. Previdência Social. 


\section{ABSTRACT}

The aim of this study is to promote a reflection on the judicial control of social security, by consulting the relevant literature. To conduct the work at hand, the periodic specialized databases were accessed, as well as rules and case law on the subject in question. In this sense, they have been identified in the case law decisions that demonstrate judicial review in the social security public policy. Also, when analyzing the provisions of norma-

\section{RESUMEN}

El objetivo de este estudio es el de promover una reflexión sobre el control judicial de la seguridad social, mediante la consulta de la bibliografía pertinente. Para llevar a cabo el trabajo a mano, se accede a las bases de datos especializadas periódicas, así como las normas y la jurisprudencia sobre el tema en cuestión. En este sentido, han sido identificados en las decisiones de abogados de casos que demuestran la revisión judicial en la política pública de seguridad social. Además, al analizar las dis- tive instructions selected in this study, it was found that those standards have been published in order to contemplate judicial commands, despite literature consulted criticizing the judicial activism and the exacerbation of social exclusion.

\section{KEYWORDS}

Judicial control. Social security. Social security. posiciones de instrucciones normativas seleccionados en este estudio, se encontró que esas normas se han publicado con el fin de contemplar órdenes judiciales, a pesar de la literatura consultada criticar el activismo judicial y la exacerbación de la exclusión social.

\section{PALABRAS CLAVE}

control judicial; la seguridad social; Seguridad Social. 


\section{INTRODUCC̣̃̃O}

O regime geral de previdência é especificado pelo fato de possuir caráter contributivo, de filiação obrigatória - excetuando-se para o segurado facultativo - sendo pautado pela preservação do equilíbrio financeiro e atuarial. 0 arcabouço legal que o baliza é constituído pela Lei no 8.212/1991 - a qual trata da organização da Seguridade Social e institui Plano de Custeio, e pela Lei no 8.213/1991, dispondo sobre os Planos de Benefícios da Previdência Social.

O objetivo do presente estudo é promover uma reflexão sobre o controle judicial da previdência social, por meio da consulta à bibliografia especializada. Para conduzir o trabalho em pauta, foram acessadas as bases de dados da Revista dos Tribunais Online, do Portal de Periódicos da Coordenação de Aperfeiçoamento de Pessoal de Nível Superior (CAPES), bem como do Google Acadêmico. Adicionalmente, foram consultadas normas e jurisprudências acerca da temática em questão. Procurou-se identificar artigos, jurisprudências e doutrinas naquelas bases de dados por meio do emprego dos seguintes descritores: "controle judicial da previdência social"; "controle social" e "previdência social".

0 trabalho é composto pelas seguintes seções: introdução; a seguridade como direito social; o controle judicial; jurisprudências; instruções normativas; considerações finais; e referências.

\section{A SEGURIDADE COMO DIREITO SOCIAL}

Sarlet (1999 APUD Krell, 1999, p. 239) argumenta que os direitos sociais são aqueles que mais têm desencadeado discussões a respeito da sua eficácia e efetividade, especialmente com relação à questão da eficiência e suficiência dos mecanismos jurídicos disponíveis para thes conferir a perfeita realização.

A Constituição Federal de 1988, no seu artigo 6², apresenta um rol de direitos sociais. "São direitos so- ciais a educação, a saúde, o trabalho, o lazer, a segurança, a previdência social, a proteção à maternidade e infância, a assistência aos desamparados, na forma desta Constituição" (BRASIL, 1988, [s.p.]).

Lopes (1998 APUD KRELL, 1999, p. 253) argumenta que os direitos sociais - notadamente saúde e educação públicas, segurança e previdência social - não são fruíveis ou exequíveis sob o prisma individual, o que não significa que, no plano jurídico, não possam, em circunstâncias específicas, ser demandados como se exigem, na esfera judicial, outros direitos subjetivos. Em regra, os serviços sociais, para que sejam eficazes, dependem da atuação do Executivo e do Legislativo por serem dotados do caráter de generalidade e publicidade.

Neste sentido, o artigo 194 da Carta Magna de 1988 traz que a "seguridade social compreende um conjunto integrado de ações”, ou seja, ações promovidas de forma programada, de modo a constituir, portanto, uma política pública estatal. Essa noção será fundamental no momento em que se começa a pensar em judicialização da seguridade social.

Insta ressaltar que a Carta Constitucional menciona um conjunto integrado de ações, logo, a seguridade social envolve um atuar positivo pelo Estado, desta forma, envolvendo prestações, sendo assim um direito prestacional, em que o cidadão pode exigir do Estado um "fazer".

Krell (1999) vislumbra que o fato de o Brasil estar entre os dez países com maior representatividade no plano econômico, ser detentor de uma carta magna sensivelmente avançada na seara dos direitos sociais e, ao mesmo tempo, possuir um contingente populacional de mais de 30 milhões de pessoas, situado abaixo da linha de pobreza representa um paradoxo. São indivíduos desamparados pelos serviços públicos de saúde e de assistência social, vivendo em circunstâncias incertas afetas a habitação e alimentação.

Há que se destacar que ademais do aspecto jurídico e social, existe também o aspecto econômico. Não se pode negligenciar que direitos geram cus- 
tos, notadamente os direitos que demandam um "fazer" da Administração Pública. Nas palavras de Wang (2008, p. 540):

\begin{abstract}
As políticas públicas para efetivação de direitos sociais demandam, na grande maioria das vezes, gasto de recursos públicos. E esse é o ponto central no debate a respeito da exigibilidade judicial dos direitos sociais, pois uma decisão judicial para a tutela de um determinado direito social no caso concreto pode obrigar o Estado a realizar gastos públicos e, uma vez que os recursos públicos disponíveis são menores do que o necessário para oferecer a todos os cidadãos todos os direitos que a Constituição prevê, muitas vezes a $\mathrm{Ad}$ ministração não tem ou não pode dispor dos recursos necessários para atender a decisão judicial sem preju dicar a tutela de um outro direito que o Poder Público entendeu ser mais importante. A escassez de recursos exige que o Estado faça escolhas, o que pressupõe preferências e que, por sua vez, pressupõe preteridos. 0 grande debate que a exigibilidade judicial dos direitos sociais suscita é a possibilidade daqueles que foram preteridos de buscarem, por meio do poder Judiciário, a tutela de seus direitos, e se esse Poder teria legitimidade democrática, competência constitucional e formação técnica para realizar essa tarefa.
\end{abstract}

Barcellos (2005, p. 91) sintetiza bem esta relação gerada entre Constituição, execução de políticas públicas, gastos públicos com recursos limitados e as consequentes escolhas por parte dos gestores, conforme abaixo:

\begin{abstract}
Visualize-se novamente a relação existente entre os vários elementos que se acaba de expor: (i) a Constituição estabelece como um de seus fins essenciais a promoção dos direitos fundamentais; (ii) as políticas públicas constituem o meio pelo qual os fins constitucionais podem ser realizados de forma sistemática e abrangente; (iii) as políticas públicas envolvem gasto de dinheiro público; (iv) os recursos públicos são limitados e é preciso fazer escolhas; logo (v) a Constituição vincula as escolhas em matéria de políticas públicas e dispêndio de recursos públicos.
\end{abstract}

Por fim, cabe fazer um esclarecimento acerca da Seguridade Social. Esta, na verdade, é um gênero que comporta três espécies: saúde, assistência social e previdência social. Estas espécies apresentam algumas diferenças entre si.
A partir do artigo 196 da Constituição da República, é possível se perceber que o direito à saúde no Brasil apresenta duas características marcantes: é um direito universal e gratuito. Assim, não se vincula o acesso à prestação de saúde à necessidade ou ao pagamento de qualquer contribuição. Tanto os mais abastados quanto aos que vivem em situação de extrema pobreza possuem direito ao serviço público de saúde. Há um direito subjetivo público à saúde.

Já a assistência social é conceituada pela Lei Orgânica da Assistência Social (LOAS) como sendo a "Política de Seguridade Social não contributiva, que provê os mínimos sociais, realizada através de um conjunto integrado de ações de iniciativa pública e da sociedade, para garantir o atendimento às necessidades básicas".

Esta assistência busca resgatar o status de cidadania do indivíduo e é prestada apenas a quem dela necessitar, independentemente de contribuição à seguridade social, conforme o artigo 203 da Constituição. Em que pese a correspondência quanto à gratuidade, verifica-se claramente a diferença quanto ao seu raio de atuação. Enquanto a saúde é um direito de todos, a assistência social só é prestada a quem dela necessitar.

Finalmente, a previdência social é verdadeiramente um seguro social, pelo qual o indivíduo será protegido contra alguns riscos sociais. E como tal, a previdência, diferentemente da saúde e da assistência social, é contributiva, ou seja, há que se pagar uma determinada contribuição, a fim de se obter a cobertura pelos riscos previamente definidos. Pelo artigo $3^{\circ}$ da Lei 8.212/91, estes riscos são: incapacidade, idade avançada, tempo de serviço, desemprego involuntário, encargos de família e reclusão ou morte daqueles de quem dependiam economicamente. Feitas estas distinções, este trabalho tem como escopo apenas este último ramo da seguridade social.

\section{CONTROLE JUDICIAL}

Inicialmente, é inconteste que nos dias hodiernos há uma tendência mundial à judicialização dos con- 
flitos. No Brasil, isso se tornou mais assente a partir da redemocratização observada a partir da década de 1980. Barroso (2009, p. 19) explica esta passagem da seguinte forma:

Judicialização significa que algumas questões de larga repercussão política ou social estão sendo decididas por órgãos do Poder Judiciário, e não pelas instâncias políticas tradicionais: o Congresso Nacional e o Poder Executivo - em cujo âmbito se encontram o Presidente da República, seus ministérios e a administração pública em geral. Como intuitivo, a judicialização envolve uma transferência de poder para juízes e tribunais, com alterações significativas na linguagem, na argumentação e no modo de participação da sociedade. O fenômeno tem causas múltiplas. Algumas delas expressam uma tendência mundial; outras estão diretamente relacionadas ao modelo institucional brasileiro.

Igualmente, indubitável que o auge desse processo se deu com a promulgação da Constituição da República em 1988. Carvalho (2010) argumenta que a Carta Magna de 1988 apresenta como uma das suas primazias o princípio constitucional da inafastabilidade do controle jurisdicional ou da jurisdição, ou o igualmente denominado amplo acesso ao Poder Judiciário, que materializa um dos direitos e garantias fundamentais do cidadão, seja na procura por seus direitos, seja na salvaguarda dos seus interesses. Verissimo (2008, p. 413) também concorda com o fato de a Constituição de 1988 ter contribuído sobremaneira para o processo de judicialização na sociedade brasileira, conforme se depreende de suas palavras:

[...] a Constituição de 1988 está na base do processo de judicialização da vida pública brasileira, tendo sido responsável por desenhar a face protagônica que a justiça e o STF em particular ostentariam a partir da década de 1990, seus mecanismos de ampliação do acesso à justiça, aliados à aparente disposição dos tribunais em exercer ativamente as competências de revisão que lhes foram atribuídas, também respondem, em contrapartida, por boa parte da crise de eficiência que acompanhou a atuação do Judiciário a partir dessa mesma década.

Para Moraes (1999 APUD CAMBI; OSIPE, 2014, p. 3), a atuação judicial na efetivação dos direitos previ- denciários tem possibilidade de ser mais benéfica que a administrativa, especialmente nas situações mal solucionadas pela aplicação literal da lei. Esse controle de juridicidade representa o corolário do princípio da legalidade e da possibilidade de revogação do ato administrativo ilegal.

Lopes (2009) entende que o controle realizado pelo Poder Judiciário sobre a Administração Pública refere-se somente ao controle de legalidade, devendo o juiz se colocar na posição de servidor público e nessa posição adotar o seguinte pensamento: à luz do arcabouço legal, o benefício deveria ser disponibilizado?

Trata-se do motivo pelo qual o processo em que não haja corroboração de requerimento administrativo deve ser extinto sem julgamento do mérito, por ausência de interesse de agir, na modalidade necessidade, conforme preconiza o enunciado 77 do Fórum Nacional dos Juizados Especiais Federais (FONAJEF). Não existindo ilegalidade, não haveria controle judicial a ser realizado. Não bastasse isso, quando o órgão colegiado for distanciar a incidência de uma norma legal, faz-se imperiosa a reserva de plenário (art. 97, da CRFB/88), conforme estabelece a Súmula Vinculante de $\mathrm{n}^{0} 11$ do STF.

O estudo realizado por Silva (2012) ratifica a relevância do Judiciário na salvaguarda dos direitos constitucionais, sem ignorar a necessidade de aperfeiçoamento dos instrumentos de controle judicial e de conexão entre os três poderes para ações em favor da efetivação dos direitos sociais. Nesse contexto, destaca-se a necessidade de se promover uma reflexão acerca do papel desse poder, uma vez que, além de o Judiciário não concorrer para o incremento da justiça social e para a redução da desigualdade brasileira, acaba por revelar-se como mais um instrumento de enraizamento da exclusão social.

Segundo Bicca (2011, p. 159), a expressão “ativismo judicial”, apesar de não possuir uma conceituação clara acerca do seu significado, vem sendo empregada com frequência nos exames do comportamento judicial efetuados por distintos segmentos. Verifica-se que o "ativismo judicial" tornou-se um lugar-comum utilizado para censurar o comportamento judicial assumido por uma 
Corte ou uma decisão judicial específica, sendo que existem poucas conexões benéficas a tal evento.

Quando se empreende a análise dessa teoria à luz das políticas públicas, Bicca (2011, p. 160) passa a considerar que o "ativismo judicial" se dá quando se verifica o desrespeito à discrição do legislador na estruturação da política pública, cindindo-se a legislação regulamentadora cuja elaboração baseou-se em parâmetros razoáveis e autorizados pela Constituição, alterando-se sensivelmente a política por meio do emprego dos critérios próprios do juiz. Já Barroso (2009, p. 22) trabalha esta questão da seguinte maneira:

A idéia [sic] de ativismo judicial está associada a uma participação mais ampla e intensa do Judiciário na concretização dos valores e fins constitucionais, com maior interferência no espaço de atuação dos outros dois Poderes. A postura ativista se manifesta por meio de diferentes condutas, que incluem: (i) a aplicação direta da Constituição a situações não expressamente contempladas em seu texto e independentemente de manifestação do legislador ordinário; (ii) a declaração de inconstitucionalidade de atos normativos emanados do legislador, com base em critérios menos rígidos que os de patente e ostensiva violação da Constituição; (iii) a imposição de condutas ou de abstenções ao Poder Público, notadamente em matéria de políticas públicas.

Rosenn (2002) destaca que a incoerência do controle da constitucionalidade no Brasil está associada ao fato de que, a despeito de possuir uma Constituição farta de pormenores e um sistema de controle judicial bem estruturado, diversas garantias constitucionais ainda não foram efetivadas e outras são frequentemente transgredidas impunemente.

Independentemente da avaliação mais positiva ou mais negativa que uma determinada sociedade possa fazer não se pode negar que o "ativismo judicial" se tornou um fenômeno social cada vez mais presente na vida cotidiana do cidadão e que, à luz do ordenamento atual, parece se tratar de uma tendência irreversível. Nas palavras de Teixeira (2012, p. 52):

Mais importante do que estabelecer uma definição conceitual dogmaticamente precisa de ativismo judicial ou então bradar contra toda e qualquer espécie sua, devemos reconhecer que se trata de uma patologia constitucional cada vez mais necessária - desde que seja na sua vertente positiva -, para a proteção do indivíduo contra omissões ou excessos do Estado. Hipoteticamente, a partir de um critério de negação, o que ocorreria se também o Judiciário decidisse abandonar uma postura ativista e passasse a se omitir diante das ofensas aos direitos fundamentais que muitas vezes são perpetradas pelo próprio Estado? A quem restaria recorrer?

O foco deste trabalho ficará mais restrito à última conduta delineada por Barroso, em que há uma imposição de "fazer" ou "não fazer" por parte do Poder Judiciário à Administração Pública, quando do controle da formulação e execução de políticas públicas no âmbito da previdência social.

\section{JURISPRUDÊNCIAS SELECIONADAS}

A jurisprudência selecionada abaixo aponta para o controle judicial da política pública na seara previdenciária.

1) STF - ADIn 1.946-5 - j. 29/4/1999 - julgado por Sydney Sanches - Área do Direito: Constitucional; Civil; Processual; Previdenciário.

LICENÇA MATERNIDADE - Limitação salarial - Inadmissibilidade - Emenda Constitucional 20 de 1998 que estipula o limite máximo de R\$ $1.200,00$ para pagamento de benefícios previdenciários - Aplicação da referida norma que imputaria ao empregador o custeio concernente à diferença do valor do benefício, de modo a estimular a opção deste pelo trabalhador masculino e propiciar discriminação sexual vedada pela Constitucional Federal.

RELATOR : MIN. SYDNEY SANCHES

REQTE. : PARTIDO SOCIALISTA BRASILEIRO - PSB

ADVDA. : VALESKA MONTEIRO DE MELO

REQDAS. : MESAS DA CÂMARA DOS DEPUTADOS E DO SENADO FEDERAL

REQDO. : MINISTRO DE ESTADO DA PREVIDÊNCIA E ASSISTÊNCIA SOCIAL

Decisão: 0 Tribunal, por votação majoritária, acolheu a preliminar suscitada pelo Ministro da Previdência e 
Assistência Social e, em consequência, não conheceu da ação direta quanto ao art. $6^{\circ}$ da Portaria MPAS $n^{\circ}$ $4.883 / 98$, restando prejudicada, desse modo, a apreciação do pedido de medida cautelar, vencidos os Ministros Marco Aurélio, Carlos Velloso, Sepúlveda Pertence e Néri da Silveira, que dela conheciam. Votou o Presidente. 0 Tribunal, por votação unânime, rejeitou a outra preliminar suscitada pelo Presidente do Senado Federal, por entender que se revela juridicamente possível a fiscalização abstrata de constitucionalidade que tenha por objeto emenda à Constituição (a EC n ${ }^{0}$ 20/98, no caso) alegadamente vulneradora das cláusulas pétreas inscritas no art. $60, \S 4^{\circ} \mathrm{da}$ Constituição da República (LGL\1988\3). Votou o Presidente. Em seguida, o julgamento foi adiado para prosseguimento na próxima sessão. Plenário, 07.4.99.

Decisão: Prosseguindo no julgamento, o Tribunal, por unanimidade, deferiu a medida cautelar para, dando interpretação conforme à Constituição ao art. 14 da Emenda Constitucional $n^{0} 20$, de 15/12/1998, deixar expresso que a citada disposição não se aplica à licença maternidade a que se refere 0 art. $7^{\circ}$, inciso XVIII da Carta Magna (LGL\1988\3), respondendo a Previdência Social pela integralidade do pagamento da referida licença, nos termos do voto do Relator. Votou o Presidente. Ausentes, justificadamente, os Srs. Ministros Celso de Mello (Presidente) e Moreira Alves. Presidiu o julgamento o Sr. Ministro Carlos Velloso (Vice-Presidente). Plenário, 29.4.99. 2) TJMG - MS 0024.12.129.593-5 - j. 3/10/2012 - julgado por Geraldo Claret de Arantes - DJe 5/10/2012 - Área do Direito: Constitucional; Processual; Previdenciário

CONTROLE DIFUSO DE CONSTITUCIONALIDADE - EC 41/2003 - Inconstitucionalidade - Constatação no julgamento da APn 470, conhecida como "Caso Mensalão", de que a reforma previdenciária, aprovada no Parlamento, ocorreu mediante compra de votos dos parlamentares - Emenda constitucional maculada ab initio, de forma irreversível, que é considerada inválida ante o vício de decoro.

PREVIDÊNCIA SOCIAL - Mandado de segurança - Servidor público - Benefício previdenciário - Pensão por morte - Reajuste do pensionamento sem levar em conta o novo critério implementado com o advento de EC 41/2003 Admissibilidade - Alteração legislativa que representa verdadeiro confisco aos direitos adquiridos - Vício formal que macula ato do poder reformador, desde a origem Violação de direito líquido e certo que se evidencia.

Ementa da Redação: Mandado de segurança. Previdência Social. Servidor público. Reajuste de benefí- cio. Ato do Diretor de Previdência e do Presidente do Instituto de Previdência dos Servidores Públicos do Estado de Minas Gerais - IPSEMG. Beneficiária de pensão por morte, que pleiteia reajuste, alegando que o cálculo da benesse deve observar as regras constantes do art. 40 , § 7..$^{\circ}$, I, da CF/1988, com critério de paridade. Fato gerador posterior ao advento da EC 42/2003. Possibilidade.

Ante todo o exposto, concedo a segurança, e exercendo o controle difuso da constitucionalidade, no caso concreto, declarando inconstitucional, por vício de decoro a EC 41/2003 e todas as alterações, constitucionais ou não, que confisquem direitos adquiridos pelo servidor público, mediante condição e termo da época da investidura, e para condenar as autoridades coatoras a procederem 0 pagamento, à autora, da pensão no valor integral, correspondente hoje a R\$ 4.801,64 (quatro mil, oitocentos e um reais e sessenta e quatro centavos), com efeito ex tunc, ou seja, do fato gerador do benefício, com as correções devidas e com juros de meio por cento ao mês, desde a data de cada pagamento confiscado.

Custas, na forma da lei.

Sem condenação em honorários, porquanto incabível em sede de mandado de segurança, nos termo da Súmula 105 (MIX 2010\1358) do STJ e 512 do STF. Publique-se. Registre-se. Intimem-se.

Belo Horizonte, 03 de outubro de 2012 - GERALDO CLARET DE ARANTES, Juiz de Direito.

\section{INSTRUÇ̃ES NORMATIVAS SELECIONADAS}

De modo análogo ao observado em relação às jurisprudências selecionadas, as instruções normativas elencadas abaixo evidenciam que houve a alteração da normatização por força judicial.

INSTRUÇÃO NORMATIVA 9, DE 8 DE AGOSTO DE 2006, DO INSTITUTO NACIONAL DO SEGURO SOCIAL - INSS Procedimentos a serem adotados em cumprimento à decisão judicial constante dos autos da Ação

Civil Pública 9700579026, em trâmite na $7^{\text {a }}$ Vara Federal Previdenciária de São Paulo/SP.

O Presidente do Instituto Nacional do Seguro Social INSS, no uso da competência que the confere o Decreto 5.513, de 16 de agosto de 2005 (LGL\2005\1310), Considerando a decisão judicial proferida na Ação Civil Pública 97.0057902-6, em trâmite na $7^{\text {a }}$ Vara Federal de São Paulo/SP, resolve: 
Art. $1^{\circ}$

Determinar, em âmbito nacional, que o INSS se abstenha de indeferir os pedidos de inscrição, na condição de dependente, de crianças e adolescentes que, por determinação judicial, estejam sob a guarda de segurado do Regime Geral de Previdência Social RGPS, para os fins previstos na Lei 8.213 , de 24 de julho de 1991, e no Regulamento da Previdência Social - RPS, aprovado pelo Decreto 3.048, de 6 de maio de 1999.

Parágrafo único. A inscrição na condição de dependente, de acordo com o disposto no caput, não afasta os demais requisitos previstos no $\S 3^{\circ}$, art. 16 do RPS para concessão de benefícios, inclusive para comprovação da dependência econômica.

Art. $2^{\circ}$

As decisões judiciais, proferidas nas Ações Civis Públicas 1999.38.00.004900-0/29a Vara Federal da Seção Judiciária de Minas Gerais e 1999.43.00.000326-2/1ª Vara Federal da Seção Judiciária de Tocantins, continuam em vigor, de forma que as Agências da Previdência Social - APS, nesses Estados da Federação, deverão continuar a cumprir as determinações judiciais delas decorrentes, constantes da Instrução Normativa 106 INSS/DC, de 14 de abril de 2004. Além dessas decisões, as APS nos referidos Estados encontram-se sujeitas, também, ao cumprimento da decisão prolatada na Ação Civil Pública 97.0057902-6, da $7^{\text {a }}$ Vara Federal de São Paulo/SP.

Art. $3^{\circ}$

A sentença prolatada nos autos da ACP 98.0000595-1, em trâmite perante a $1^{\text {a }}$ Vara Federal da Seção Judiciária de Sergipe/SE, ante o provimento do Recurso Especial 720706/SE, perdeu seus efeitos. Dessa forma, as APS no Estado de Sergipe deverão cumprir a decisão proferida nos autos da ACP 97.0057902-6, da $7^{\text {a }}$ Vara Federal de São Paulo/SP.

Art. $4^{\circ}$

Os efeitos deste Ato são extensivos a todo o território nacional e retroagem a 8 de junho de 2006 , data do recebimento do ofício que ordenou o cumprimento da decisão judicial, na Diretoria de Benefícios, e os procedimentos nele definidos devem ser aplicados em todos os processos de benefícios requeridos a partir dessa data, tanto para os pendentes de decisão final, quer em primeira instância administrativa, quer em instância recursal, bem como para os pedidos de revisão de benefícios.

Parágrafo único. Enquanto vigorar a decisão judicial, fica suspensa a aplicação dos arts. 23, 235, 272 e 296 da Instrução Normativa 118 INSS/DC, de 14 de abril de 2005.

Parágrafo único
*A Instrução Normativa INSS 118/2005

(LGL\2005\216) foi revogada pela Instrução Normativa INSS 11/2006 (LGL\2006\237).

Art. $5^{\circ}$

A Diretoria de Benefícios e a Empresa de Tecnologia e Informações da Previdência Social - DATAPREV, estabelecerão mecanismos de controle para os procedimentos estabelecidos nesta Instrução Normativa.

Parágrafo único. Para os benefícios concedidos a partir de 8 de junho de 2006, deverá ser informado no sistema de benefícios o número da Ação Civil Pública cuja decisão está sendo cumprida, de acordo com as instruções definidas nos arts. $2^{\circ}$ e $3^{\circ}$ desta Instrução Normativa.

Art. $6^{\circ}$

Este Ato entra em vigor na data da sua publicação. Valdir Moysés Simão

INSTRUÇÃO NORMATIVA 106, DE 14 DE ABRIL DE 2004, DO INSTITUTO NACIONAL DO

SEGURO SOCIAL - INSS

Procedimentos a serem adotados nos Estados de Minas Gerais, São Paulo, Sergipe e Tocantins, em cumprimento de decisões judiciais, para a inscrição e concessão de benefícios do Regime Geral de Previdência Social ao menor sob guarda judicial de segurado. FUNDAMENTAÇÃO LEGAL:

Lei 8.212, de 24/7/1991, e alterações posteriores; Lei 8.213, de 24/7/1991, e alterações posteriores; Lei 9.528, de 10/12/1997 (LGL\1997\101);

Decreto 3.048, de 6/5/1999, e alterações posteriores; Ação Civil Pública 97.0057902-6;

Ação Civil Pública 98.0000595-1;

Ação Civil Pública 1999.38.00.004900-0;

Ação Civil Pública 1999.43.00.000326-2.

O Diretor-Presidente do Instituto Nacional do Seguro Social (INSS), no uso da competência que the é conferida pelo inciso IV, artigo 32, Anexo I da Estrutura Regimental aprovada pelo Decreto 4.688, de 7 de maio de 2003 (LGL\2003\220),

Considerando as decisões judiciais, ainda em vigor, proferidas nas ações civis públicas 1999.38.00.004900-0, da $29^{a}$ Vara Federal da Seção Judiciária de Minas Gerais; 97.0057902-6, da $1^{\text {a }}$ Vara Federal da Seção Judiciária de São Paulo; 98.0000595-1, da $1^{\text {a }}$ Vara Federal da Seção Judiciária de Sergipe e 1999.43.00.0003262, da $1^{a}$ Vara Federal da Seção Judiciária de Tocantins, todas propostas pelo Ministério Público Federal, resolve:

Art. $1^{\circ}$

Determinar que o INSS se abstenha de indeferir os pedidos de inscrição, na condição de

dependente, de crianças e adolescentes que, por de- 
terminação judicial, estejam sob a guarda de segurado do Regime Geral de Previdência Social, para os fins previstos na Lei 8.213/1991 e no Regulamento da Previdência Social, aprovado pelo Decreto 3.048/1999. Parágrafo único. A inscrição na condição de dependente, de acordo com o disposto no caput, não afasta os demais requisitos previstos no parágrafo $3^{\circ}$, artigo 16 do Decreto 3.048/1999, para a concessão de benefícios, inclusive para a comprovação da dependência econômica.

Art. $2^{\circ}$

A Diretoria de Benefícios e a Empresa de Tecnologia e Informações da Previdência Social-Dataprev, estabelecerão mecanismos de controle para os procedimentos estabelecidos nesta Instrução Normativa.

Art. $3^{\circ}$

Os efeitos deste Ato são restritos aos Estados de Minas Gerais, São Paulo, Sergipe e Tocantins, onde ficam suspensas, enquanto vigorarem as respectivas decisões judiciais, a aplicação dos artigos 15, 233, 271 e 290 da Instrução Normativa 95 INSS/DC, de 7 de outubro de 2003, e os seus procedimentos devem ser aplicados em todos os processos de benefícios pendentes de decisão final, quer em primeira instância administrativa, quer em instância recursal, bem como para os pedidos de revisão de benefícios.

Art. $4^{\circ}$

Esta Instrução Normativa entra em vigor na data da sua publicação e revoga a Instrução Normativa 64 INSS/DC, de 31 de janeiro de 2002.

\section{CONSIDERAÇÕES FINAIS}

0 objetivo do presente estudo foi promover uma reflexão sobre o controle judicial da previdência social, por meio da consulta à bibliografia especializada, normas e jurisprudência. Nesse sentido, foram identificadas na jurisprudência decisões que evidenciam o controle judicial na política pública previdenciária.

Adicionalmente, ao se analisar os dispositivos de instruções normativas selecionadas na presente pesquisa, verificou-se que aquelas normas foram publicadas de modo a contemplarem comandos judiciais, a despeito de a literatura consultada formular críticas ao ativismo judicial e à exacerbação da exclusão social.

Em última análise, convém registrar que a principal limitação do estudo é o fato de que a pesquisa não teve a pretensão de esgotar o assunto, especialmen- te em função do tempo limitado para a realização da investigação. $\mathrm{Na}$ avaliação do autor, representou um oportuno exercício didático de fixação de conceitos basilares acerca da temática em pauta.

\section{REFERÊNCIAS}

BARCELLOS, Ana Paula de. Neoconstitucionalismo, direitos fundamentais e controle das políticas públicas. Revista de Direito Administrativo, v.240, 2005. p.83-105.

BARROSO, Luís Roberto. Judicialização, ativismo judicial e legitimidade democrática. Anuario Iberoamericano de Justicia Constitucional, n.13, 2009. p.17-32.

\section{BICCA, C.S. $\mathbf{0}$ ativismo judicial no controle das} políticas públicas: o caso da assistência social no Brasil. Instituto Brasiliense de Direito Público. 2011. 171f. Dissertação (Mestrado em Direito Constitucional) - Instituto Brasiliense de Direito Público - IDP, Brasília, 2011.

CAMBI, E.A.S.; OSIPE, N.B.. Colaboração no processo previdenciário. Revista de Processo, v.228, 2014. p.283-310.

CARVALHO, M.C. O requerimento administrativo prévio não é condição da ação nas ações previdenciárias. Revista de Direito do Trabalho, v.139, São Paulo, 2010. p.77-101.

KRELL, Andreas J. Realização dos direitos fundamentais sociais mediante controle judicial da prestação dos serviços públicos básicos (uma visão comparativa). Revista de Informação Legislativa, v.144, Brasília (DF), 1999. p.239-260.

LOPES, C.C.V. Análise crítica da atuação do Poder Judiciário em relação aos benefícios da Seguridade Social. Revista da EMERJ, v.12, n.47, 2009. 
ROSENN, Keith S. O controle da constitucionalidade no Brasil: desenvolvimentos recentes. Tradução de Carlos Jorge Sampaio Costa. Revista de Direito Administrativo, 2002.

SILVA, N.L.A judicialização do Benefício de Prestação Continuada da Assistência Social. Serviço Social \& Sociedade, v.1, 2012. p.555-575.

TEIXEIRA, Anderson Vichinkeski. Ativismo judicial: nos limites entre racionalidade jurídica e decisão política. Revista Direito GV, v.8, n.1, 2012. p.037-057.

VERISSIMO, Marcos Paulo. A Constituição de 1988, vinte anos depois: Suprema Corte e ativismo judicial “à brasileira”. Revista Direito GV, v.4, n.2, 2008. p.407-440.

WANG, Daniel Wei Liang. Escassez de recursos, custos dos direitos e reserva do possível na jurisprudência do STF. Revista Direito GV, v.4, n.2, 2008. p.539-568. 
1 Doutorando em Ambiente e Desenvolvimento - UNIVATES; Mestre em Ciências Contábeis - Faculdade de Administração e Finanças da Universidade do Estado do Rio de Janeiro; Especialista em Comércio Exterior - Instituto de Economia da Universidade Federal do Rio de Janeiro; Especialista em Gerenciamento de Projetos - Fundação Getúlio Vargas; Bacharel em Administração - Universidade Cândido Mendes e em Ciências Navais, com Habilitação em Administracão de Sistemas - Escola Naval; Atualmente é Oficial Superior da Ativa do Corpo de Intendentes da Marinha do Brasil, ocupa o posto de Capitão de Corveta e desempenha a função de Chefe do Departamento de Sistemas de Pagamento da Pagadoria de Pessoal da Marinha; Membro do Corpo Editorial da Revista PAGMAR (ISSN 2318-1702 versão impressa e ISSN 2446-4791 versão on-line). E-mail: rsantiago79@ hotmail.com.

2 Mestre em Ciências Contábeis pela Universidade do Estado do Rio de Janeiro - UERJ (2013); Bacharel em Direito pela Faculdade de Direito de Vila Velha (2008); Bacharel em Ciências Navais (Habilitação em Administração) pela Escola Naval (1995); Especialização em Administração - CIAW (1996); Aperfeiçoamento para Oficiais Intendentes, Gestão Pública - CIAW (1998); Exerceu os cargos públicos de Oficial da Marinha do Brasil, Auditor Fiscal de Tributos do Estado de Alagoas e, atualmente, é Auditor Fiscal da Receita do Estado do Espírito Santo; Tem experiência em Ciências Contábeis, em Administração Financeira e Orçamentária, em Processo Administrativo Fiscal (PAF) e em Fiscalização de Tributos. E-mail: robsonconde@hotmail.com

3 Especialista em Gestão Pública - Faculdade de Administração e Ciências Contábeis da Universidade Federal do Rio de Janeiro; Especialista em Atividades de Intendência - Centro de Instrução e Adestramento Almirante Newton Braga; Bacharel em Direito - Faculdade Nacional de Direito - Universidade Federal do Rio de Janeiro e em Ciências Navais, com Habilitação em Administração de Sistemas - Escola Naval; Atualmente é Oficial Intermediário da Ativa do Corpo de Intendentes da Marinha do Brasil, ocupa o posto de Capitão-Tenente e desempenha a função de Encarregado da Subseção de Abastecimento do Comando do $4^{\circ}$ Distrito Naval. E-mail: jorginhotesch@hotmail.com

Data da submissão: 02 de setembro de 2016 Avaliado em: 12 de outubro de 20156 (Avaliador A) Avaliado em: 22 de novembro de 2016 (Avaliador B) Aceito em: 23 de dezembro de 2016

\begin{abstract}
4 Doutorando em Engenharia de Produção - UFF, desenvolvendo pesquisa sobre "Cálculo Atuarial das Pensões dos Militares das Forças Armadas Brasileiras: Análise e Avaliação de Cenários Prospectivos"; Mestre em Engenharia de Produção pela COPPE - UFRJ; Licenciado em Matemática e Especialista em Instrumentação Matemática - UFF; Bacharel em Ciências Navais - Escola Naval, com habilitação em Engenharia de Sistemas. E-mail: marcosdossantos_doutorado_uff@yahoo.com.br
\end{abstract}


